\title{
Vulnerability of Consumption Growth in Rural India
}

\author{
Raghbendra Jha \\ Research School of Pacific \& Asian Studies \\ The Australian National University
}

May 2006

Keywords: India, Consumption Volatility, National Sample Survey, Certainty Equivalent Consumption

JEL Classification Code: D12, D18, D69, O12, Q18

Correspondence to:

Prof. Raghbendra Jha

Australia South Asia research Centre,

Division of Economics,

RSPAS, Australian National University,

Canberra, ACT 0200, Australia

Telephone: 61261252683

Fax: 61261250443

Email: r.jha@anu.edu.au

\footnotetext{
* Thanks are due to Raghav Gaiha for introducing me to this literature and for helpful comments. The views expressed here are those of the author alone. .
} 


\begin{abstract}
The fragility of livelihoods and hence the vulnerability of consumption growth due to aggregate shocks in the Indian rural sector have been highlighted recently. However, as yet there exist no estimates of the vulnerability of consumption growth in rural India. This paper attempts to fill this lacuna by providing certainty equivalent growth of consumption in 14 major states of India over the period 1958-1997, corresponding to NSS Rounds $13^{\text {th }}$ to $53^{\text {rd }}$. The extant debates around poverty-growth elasticities are premised on the assumption of a state of world without any risks and uncertainties. In the real world in which the poor actually live they are subject to risks - both general and idiosyncratic - which affect their welfare. Thus poverty should not be viewed in static terms but within a framework that allows for changing states of the world. This paper shows that certainty equivalent consumption growth in rural India has been much lower than average real per capita consumption growth - indeed, in some cases, it has been negative. This points to the poor performance of consumer-perceived average welfare in India's rural sector and should be a matter of urgent policy concern.
\end{abstract}




\section{Introduction}

India's rural sector has been subject to many and repeated shocks over time - floods, droughts, epidemics, erosion of top soil, lowering of water table — to name just a few. Whereas much has been written about the evolution of real state gross domestic products of Indian states, relatively little has been reported about the behaviour of consumption and welfare implications thereof. In fact, consumption has, more often than not, been considered only in the aggregate in macroeconomic analysis. ${ }^{1}$ What is undeniable, however, is that average consumption, with relatively small changes in distribution, is linked to living standards and is, therefore, a welfare measure of critical importance.

In the extant literature either income or consumption expenditures as measured over short periods of time (say a year) have been regarded as proxies for the material well-being of households. However, economists have long recognised that a household's sense of well-being depends not just on its average income or expenditures, but also on the risks it faces. Further, the concept of poverty should not be visualised in a static context but should permit changes in the states of nature and uncertainty of consumption outcomes. These alter the vulnerability of the household and affect its sense of well-being.

In this paper I provide estimates of the vulnerability of the consumption of rural households in India and compute average as well as certainty equivalent growth rates of consumption for representative (average) households for fourteen major

\footnotetext{
${ }^{1}$ For an early and insightful analysis of the impact of macroeconomic risks on poverty in India see Datt and Ravallion (1997).
} 
states: Andhra Pradesh, Assam, Bihar, Gujarat, Karnataka, Kerala, Madhya Pradesh, Maharashtra, Orissa, Punjab, Rajasthan, Tamilnadu, Uttar Pradesh and West Bengal. Mean real consumption for these states for the following National Sample Survey (NSS) Rounds (years in parentheses) are analysed: $13^{\text {th }}(1958), 14^{\text {th }}(1959), 15^{\text {th }}$ (1960), $16^{\text {th }}(1961), 17^{\text {th }}(1962), 18^{\text {th }}(1964), 19^{\text {th }}(1965), 20^{\text {th }}(1966), 21^{\text {st }}(1967), 22^{\text {nd }}$ (1968), $23^{\text {rd }}(1969), 24^{\text {th }}(1970), 25^{\text {th }}(1971), 27^{\text {th }}(1973), 28^{\text {th }}(1974), 32^{\text {nd }}(1978), 38^{\text {th }}$ (1984), $42^{\text {nd }}(1987), 43^{\text {rd }}(1988), 45^{\text {th }}(1990), 46^{\text {th }}(1991), 48^{\text {th }}(1993), 50^{\text {th }}(1994), 51^{\text {st }}$ (1995), 52 $2^{\text {nd }}(1996)$ and $53^{\text {rd }}(1997)$. Consumption figures for later rounds are not used in view of the well-known difficulties of comparing consumption data for the $55^{\text {th }}$ Round with those of earlier rounds.

The plan of the paper is as follows. In section II I briefly survey the empirical literature on vulnerability. I make a distinction between measures based on household level data and measures based on aggregate data when household level data is not usable. A measure of vulnerability based on such aggregate data is discussed in Section III. Section IV discusses results on vulnerability for these fourteen states. Section V concludes.

\section{Brief Overview of the Empirical Literature on Vulnerability}

Extant literature has distinguished between three forms of vulnerability (Hoddinott and Quisumbing 2003a, 2003b) - (i) vulnerability as expected poverty (VEP) or an ex ante measure of vulnerability; (ii) vulnerability as expected low utility (VEU) or an ex post measure of vulnerability; and (iii) Vulnerability as Uninsured Exposure to Risk (VER) 


\section{VEP}

VEP was first proposed by Chaudhuri et al. (2002). Vulnerability is here considered as the probability that a household will fall into poverty in the future. Thus we have: $V_{i t}=\operatorname{Pr}\left(c_{i, t+1}=z\right)$

where $\mathrm{V}_{\mathrm{it}}$ is the vulnerability of household $i$ at time $t . \mathrm{c}_{\mathrm{i}, t+1}$ is this household's consumption at time $\mathrm{t}+1$ and $\mathrm{z}$ is a poverty line. This is readily extended to the case where vulnerability rises with the length of the time horizon. Define $\mathrm{R}_{\mathrm{i}}(\mathrm{n}, \mathrm{z})$ as the probability of observing at least one spell of poverty for $n$ periods and write:

$$
R_{i}(n, z)=1-\left[\left(1-\left(P\left(c_{i, t+1}\right)<z, \ldots,\left(1-P\left(c_{, t+n}\right)<z\right)\right)\right]\right.
$$

This methodology then uses I(.) as an indicator equalling 1 if the condition is true and zero otherwise and considers household to be vulnerable if risk in $n$ periods is greater than a threshold level of probability, $p$. Thus we have:

$V_{i}(p, n, z)=I\left\{R_{i t}(n, z)>p\right\}$

Empirically Chaudhuri et al. (2002) estimate ex ante vulnerability by modelling a household consumption function for cross section data:

$$
\ln c_{i}=X_{i} \beta+\varepsilon_{i}
$$

where $c_{i}$ is per capita consumption expenditure for the ith household, $\mathrm{X}_{\mathrm{i}}$ represents a bundle of observable household characteristics, $\beta$ is a vector of parameters and $\varepsilon_{\mathrm{i}}$ is a zero-mean disturbance term that captures idiosyncratic shocks (household level shocks such as illness of main income earner) that contribute to differences in per capita consumption levels. The variance of the error term is defined as:

$$
\sigma_{\phi, i}^{2}=X_{i} \theta
$$

Estimation assumes that $c_{i}$ is normally distributed and estimates of $\beta$ and $\theta$ are obtained using a three-step feasible generalised least squares (FGLS) methodology. 
Using these estimated values the expected log consumption and the variance of the $\log$ consumption for each household as follows:

$\hat{E}\left[\ln c_{i} \mid X_{i}\right]=X_{i} \hat{\beta}$ and $\hat{V}\left[\ln c_{i} \mid X_{i}\right]=X_{i} \hat{\beta}$

The probability that a household will be poor in the future (say at at time $\mathrm{t}+1$ ) is given by:

$\hat{v}=\hat{\operatorname{Pr}}\left(\ln c_{i}<\ln z \mid X_{i}\right)=\Phi\left[\frac{\ln z-X_{i} \hat{\beta}}{\sqrt{X_{i} \hat{\theta}}}\right]$

This can be estimated using cross section data. However, it is sensitive to distributive assumptions about the error term. Further the accuracy of the estimates depends upon whether the distribution of consumption across households, given a set of characteristics at a given point in time, is an accurate representation of the timeseries variation of the consumption of the households.

\section{$\underline{\text { VEU }}$}

Ligon and Schechter (2003) define the vulnerability of a typical household as the difference between the utility from a certainty equivalent consumption $\left(\mathrm{z}_{\mathrm{ce}}\right)$ sufficient to ensure that the household is not regarded as vulnerable and the expected value of the actual utility of the household from its (risky) stream of consumption. They then define vulnerability as the sum of three components: poverty (on average), aggregate risk and idiosyncratic risk. Minimization of vulnerability is then tantamount to maximizing expected utility.

Consumption of a household $\mathrm{c}_{\mathrm{i}}$, has a distribution over different states of the world. Then vulnerability is defined as:

$\mathrm{V}_{\mathrm{i}}=\mathrm{U}_{\mathrm{h}}\left(\mathrm{Z}_{\mathrm{ce}}\right)-\mathrm{EU}_{\mathrm{i}}\left(\mathrm{c}_{\mathrm{i}}\right)$ 
where $U_{h}$ is a weakly concave, strictly increasing function. This can be rewritten as: $V_{i}=\left[U_{i}\left(z_{c e}\right)-U_{i}\left(E c_{i}\right)\right]+\left[U_{i}\left(E c_{i}\right)-E U_{i}\left(c_{i}\right)\right]$. The first term is a measure of poverty - the difference between utility from $\mathrm{z}_{\mathrm{ce}}$ and actual consumption, $c$. The second term is a measure of the risk that the household faces. As Ligon and Schechter (2003) show this term can be split up into a measure of aggregate risk and a measure of idiosyncratic risk. Thus we cane write:

$V_{i}=\left[U_{i}\left(z_{c e}\right)-U\left(E c_{i}\right)\right]($ poverty)

$+\left\{U_{i}\left(E c_{i}\right)-E U_{i}\left[E\left(c_{i} \mid \bar{x}\right)\right]\right\}($ Aggregaterisk $)$

$+\left\{E U_{i}\left[E\left(c_{i} \mid \bar{x}\right)\right]-E U_{i}\left(c_{i}\right)\right\}($ Idiosyncratic Risk $)$

\section{VER}

When risks are not managed effectively shocks result in drops in consumption and hence welfare losses. To this extent what matters is the uninsured exposure to risk. VER is an ex post measure of vulnerability. To get an estimable form of such vulnerability consider a household, $h$, living in village $v$ at time $t$. Let $\Delta \ln \mathrm{c}_{\mathrm{htv}}$ be the rate of growth of consumption per capita of this household between $t-1$ and $t$. Now write $\mathrm{S}(\mathrm{i})_{\mathrm{tv}}$ as the aggregate shock and $\mathrm{S}(\mathrm{i})_{\mathrm{htv}}$ as the idiosyncratic shock. Also write $\mathrm{D}_{\mathrm{v}}$ as a set of binary variables identifying each village and $X$ as a vector of household characteristics. The equation to be estimated for VER can be written as:

$$
\Delta \ln c_{i t v}=\sum_{i} \lambda_{i} S_{i v}+\sum_{i} \beta_{i} S_{i t v}+\sum_{i} \delta\left(D_{v}\right)+\delta_{v} X_{i t v}+\Delta \varepsilon_{i t v}
$$

Of particular interest are the parameters $\lambda$ and $\beta$ as they capture the effects of aggregate and idiosyncratic shocks, respectively.

Empirically as Gaiha and Imai (2004) argue, this can be more difficult than identifying a poor household. Vulnerability depends on the severity of shocks - both 
idiosyncratic as well as general. Typically households are better able to cope with idiosyncratic shocks as opposed to general shocks. Within the context of measurement poverty, as Gaiha and Imai argue, it is important to identify those households that become chronically poor as a result of such general shocks. This measurement necessarily involves the use of household level data. In this vein Gaiha and Imai (2006) in an important analysis assess the vulnerability of rural households in the semi-arid tropics of South India. They employ both ex ante and ex post measures of vulnerability and show that idiosyncratic risks account for the largest share (37\%), followed by poverty (35\%) and aggregate risks (22\%). Thus despite some risk sharing at the village level the rural population, particularly the landless, less educated, members of socially disadvantaged groups and small farmers, are vulnerable to idiosyncratic risks. Such risks force them to reduce consumption thus aggravating poverty and vulnerability.

\section{Measure of Vulnerability: The present paper's approach}

The ICRISAT data set used by Gaiha and Imai is unusual in that it traces the same households over a period of time. In the case of the National Sample Survey, however, this is not the case. Nevertheless, the NSS data sets have the advantages that they cover the whole country and not just the semi-arid parts as the ICRISAT data set does and that the NSS Rounds (especially the quinquennial rounds) survey a much larger number of households than the ICRISAT dataset.

In the case of the NSS data set, then, two routes are open to assessing vulnerability of consumption growth. One could use the cross section techniques of Chaudhuri et al. (2002). Doing this will, however, be subject to the criticism of this technique listed above. Also it would not be straightforward to arrive at comparable 
measures of the evolution of vulnerability over time. Alternatively, one can use a technique that focuses on the aggregate data. This ignores distributional considerations $^{2}$ but has the advantage that it provides consistent measures of vulnerability that are comparable over time.

The present paper uses the latter approach. ${ }^{3}$ This is due to Auffret (2002, 2003). He provides a framework to compute vulnerability using aggregate data. This methodology essentially involves computation of a rate of growth of real consumption with no uncertainty that would give a representative consumer the same utility as the observed (uncertain) consumption growth. The consumption of a representative individual is equated with per capita consumption and it is assumed that this (uncertain) aggregate per capita consumption follows a geometric Brownian motion with drift represented by $\frac{d c}{c}=\mu d t+\sigma d Z$ where $d Z$ is a standard Brownian motion with expectation and variance equal to 0 and $\mathrm{dt}$, respectively. The expected instantaneous per capita consumption growth is $\mu$ and $\sigma^{2}$ is the variance with $\sigma$ as the standard deviation. The standard deviation is often referred to as the volatility of real per capita consumption. Using Ito's Lemma, it can be shown that

$$
\begin{aligned}
& d(\log c)=\left(\mu-\frac{1}{2} \sigma^{2}\right) \cdot d t+\sigma \cdot d Z \text {. Hence } \\
& c_{t}=c_{0} \exp \left[\left(\mu-\frac{1}{2} \sigma^{2}\right)+\sigma[Z(t+1)-Z(t)]\right] \text { and } \\
& \log \left(\frac{c_{t+1}}{c_{t}}\right)=\left(\mu-\frac{1}{2} \sigma^{2}\right)+\sigma[Z(t+1)-Z(t)] . \text { Hence the variance of per capita }
\end{aligned}
$$

\footnotetext{
${ }^{2}$ It can be argued that ignoring distributional considerations is not a serious drawback in view of the relative stability of the Gini coefficient of consumption in these fourteen states over these rounds of the NSS (Datt and Ravallion 2002, Jha 2004).

${ }^{3}$ Estimation for NSS data sets along the lines of the cross-section analysis conducted by Chaudhuri et al. (2002) is a complementary analysis which can, fruitfully, be the subject of future research.
} 
consumption growth and the expected instantaneous consumption growth are respectively given by $\sigma^{2}=\operatorname{var}\left[\log \left(\frac{c_{t+1}}{c_{t}}\right)\right]$ and $\mu=E\left[\log \left(\frac{c_{t+1}}{c_{t}}\right)\right]+\frac{1}{2} \sigma^{2}$ where var and $E$ refer to unconditional variance and expectation. Auffret (2002) shows that this consumption process has the advantage of not violating the assumption of non-negative consumption and can be derived as the optimal outcome in a general equilibrium model with constant returns to scale technology defined by $\mathrm{dY} / \mathrm{K}=\mathrm{a} \mathrm{dt}+\mathrm{s} \mathrm{dZ}$ where $K$ represents the stock of capital, $\mathrm{dY}$ is the instantaneous output and the technological coefficients $\{\mathrm{a}, \mathrm{s}\}$ are exogenously specified constants with $\mathrm{s}>0$.

\section{Defining and Measuring Certainty-Equivalent Consumption Growth}

Following Auffet assume that

(i) Individuals have time-separable expected utility function with constant risk-aversion preferences given by $u(c)=\frac{c^{1-\rho}-1}{1-\rho}$ where $\rho>0$ and $\rho \neq 1$ is the coefficient of relative risk aversion or $u(c)=\log (c)$, the limiting case when $\rho=1$.

(ii) Per-capita consumption follows a geometric Brownian motion with drift represented by $\frac{d c}{c}=\mu d t+\sigma d Z$.

(iii) The rate of time preference is $\beta>0$.

Per-capita consumption at any time $t$ is given by $c_{t}=c_{0} \exp \left[\left(\mu-\frac{1}{2} \sigma^{2}\right)+\sigma[Z(t+1)-Z(t)]\right]$. Expected utility is 
$V\left(c_{0}, \mu, \sigma^{2}, \rho\right)=E_{0}\left[\int_{0}^{\infty} u(t) e^{-\beta t} d t\right]$ which can be rewritten as:

$V\left(c, \mu, \sigma^{2}, \rho\right)=\frac{c_{0}{ }^{1-\rho}}{1-\rho} \frac{1}{\beta+(\rho-1)\left(\mu-\frac{1}{2} \rho \sigma^{2}\right)}-\frac{1}{\beta(1-\rho)}$

the same expected utility is obtained when per capita consumption follows the deterministic process represented by

$\frac{d c}{c}=\left(\mu-\frac{1}{2} \rho \sigma^{2}\right) d t=\mu_{0}$ where $\mu_{0}=\mu-\frac{1}{2} \rho \sigma^{2} \cdot \mu_{0}$ is then defined as the certaintyequivalent consumption growth. The extant approach implicitly assumes that $\rho=0$, thereby using actual rate of growth as a measure of average welfare changes. Auffet argues that a more plausible value is $\rho=4$.

\section{Results on Vulnerability of Consumption in Rural India}

A simple plot of the growth of per capita consumption in these fourteen states (not reported here) over this time reveals that there has been much variability of pre capita consumption growth in each of these fourteen states.

Table 1 displays basic statistics on real per capita consumption growth in these fourteen states (mean growth rate, standard deviation, skewness and kurtosis) along with the computed certainty equivalent growth rates. Results are reported for decades or as close to decades as the data will permit. Four periods are chosen (i) 1960-69; (ii) 1970-78; (iii) 1984-90 and (iv) 1991-97. 
Table 1: Real Per Capita Consumption Statistics

\begin{tabular}{|c|c|c|c|c|c|}
\hline \multirow[b]{2}{*}{ State (period) } & \multicolumn{4}{|c|}{ Real Per Capita Consumption (Constant Rupees) } & \multirow{2}{*}{$\begin{array}{c}\text { Certainty Equivalent } \\
\text { Consumptiona Growth } \\
(\% \text { per year) } \\
\mu_{0}\end{array}$} \\
\hline & $\begin{array}{c}\text { Growth } \\
\text { (\% per year) } \\
\mu \\
\end{array}$ & $\begin{array}{c}\text { Standard } \\
\text { deviation } \\
\times 100 \\
\end{array}$ & Skewness & Kurtosis & \\
\hline AP 1960-69 & 0.62 & 4.99 & -0.99 & -0.08 & 0.12 \\
\hline AP 1970-78 & 4.26 & 8.17 & -0.87 & 0.43 & 2.93 \\
\hline AP 1984-90 & 4.18 & 6.73 & 0.47 & 1.02 & 3.27 \\
\hline AP 1991-97 & 5.38 & 11.10 & -0.07 & -1.05 & 2.92 \\
\hline ASSAM 1960-69 & -3.32 & 6.20 & -0.17 & -0.37 & -4.09 \\
\hline ASSAM 1970-78 & 0.36 & 6.76 & 1.56 & 2.32 & -0.55 \\
\hline ASSAM 1984-90 & 5.69 & 6.56 & 1.68 & 3.09 & 4.83 \\
\hline ASSAM 1991-97 & -1.76 & 8.24 & -0.63 & 1.34 & -3.12 \\
\hline BIHAR 1960-69 & 1.30 & 23.09 & 0.90 & 1.49 & -9.37 \\
\hline BIHAR 1970-78 & 0.75 & 3.13 & -0.06 & -1.49 & 0.55 \\
\hline BIHAR 1984-90 & 2.26 & 9.33 & 1.81 & 3.26 & 0.52 \\
\hline BIHAR 1991-97 & -0.42 & 3.81 & -1.72 & 3.50 & -0.71 \\
\hline GUJARAT 1960-69 & 0.55 & 5.57 & 0.89 & -0.06 & -0.07 \\
\hline GUJARAT 1970-78 & 2.44 & 7.11 & -0.06 & -1.35 & 1.43 \\
\hline GUJARAT 1984-90 & 2.79 & 7.30 & -0.05 & -0.84 & 1.73 \\
\hline GUJARAT 1991-97 & 1.54 & 6.54 & 0.28 & 0.61 & 0.68 \\
\hline KNTK 1960-69 & -1.87 & 13.24 & -0.16 & -0.26 & -5.38 \\
\hline KNTK 1970-78 & 3.81 & 4.56 & 0.37 & -2.34 & 3.39 \\
\hline KNTK 1984-90 & -0.74 & 7.22 & -0.50 & -1.58 & -1.78 \\
\hline KNTK 1991-97 & 3.28 & 11.59 & 0.45 & 0.73 & 0.59 \\
\hline KRL 1960-69 & 1.03 & 10.17 & -0.52 & -0.68 & -1.04 \\
\hline KRL 1970-78 & 5.00 & 13.25 & -1.49 & 3.10 & 1.48 \\
\hline KRL 1984-90 & 2.97 & 9.59 & -0.44 & -0.60 & 1.13 \\
\hline KRL 1991-97 & 1.00 & 2.09 & -0.46 & 0.82 & 0.92 \\
\hline MP 1960-69 & -1.71 & 10.28 & -0.04 & 0.15 & -3.82 \\
\hline MP 1970-78 & 1.19 & 2.59 & 0.90 & 0.71 & 1.06 \\
\hline MP 1984-90 & 5.76 & 3.39 & -0.10 & -4.70 & 5.53 \\
\hline MP 1991-97 & -1.27 & 3.85 & -0.56 & 0.99 & -1.57 \\
\hline
\end{tabular}




\begin{tabular}{|c|c|c|c|c|c|}
\hline MH 1960-69 & 0.46 & 8.22 & -1.87 & 3.55 & -0.89 \\
\hline MH 1970-78 & 6.17 & 12.05 & -0.08 & -0.32 & 3.26 \\
\hline MH 1984-90 & 0.33 & 6.06 & -0.79 & 1.84 & -0.41 \\
\hline MH 1991-97 & 0.85 & 11.26 & -0.59 & 2.05 & -1.69 \\
\hline OR 1960-69 & -1.41 & 10.22 & 0.42 & -1.13 & -3.50 \\
\hline OR 1970-78 & 2.38 & 9.73 & 0.80 & 0.76 & 0.48 \\
\hline OR 1984-90 & 6.46 & 8.03 & 0.00 & -2.83 & 5.17 \\
\hline OR 1991-97 & -0.96 & 6.47 & 0.24 & 1.53 & -1.80 \\
\hline PU 1960-69 & -0.09 & 11.57 & 0.77 & 0.49 & -2.77 \\
\hline PU 1970-78 & 4.89 & 12.97 & 0.32 & -0.06 & 1.56 \\
\hline PU 1984-90 & 4.31 & 2.36 & -0.05 & -5.03 & 4.20 \\
\hline PU 1991-97 & 3.09 & 4.92 & -1.45 & 2.33 & 2.61 \\
\hline RJ 1960-69 & -1.12 & 8.58 & -0.36 & 2.98 & -2.59 \\
\hline RJ 1970-78 & 9.39 & 22.72 & 2.01 & 4.18 & -0.93 \\
\hline RJ 1984-90 & -2.96 & 13.16 & 0.15 & 1.01 & -6.42 \\
\hline RJ 1991-97 & -1.91 & 4.65 & -1.96 & 4.12 & -2.34 \\
\hline TN 1960-69 & 0.14 & 8.56 & 0.15 & 0.18 & -1.33 \\
\hline TN $1970-78$ & 3.61 & 4.67 & 0.56 & -2.58 & 3.17 \\
\hline TN 1984-90 & 3.01 & 4.94 & 0.86 & 1.51 & 2.52 \\
\hline TN 1991-97 & 1.82 & 3.97 & 1.10 & 0.13 & 1.50 \\
\hline UP $1960-69$ & 0.50 & 14.60 & 0.19 & -0.67 & -3.76 \\
\hline UP 1970-78 & 1.87 & 13.09 & 0.75 & -1.65 & -1.56 \\
\hline UP 1984-90 & 3.57 & 10.48 & -0.23 & -3.41 & 1.37 \\
\hline UP 1991-97 & -1.49 & 5.79 & -1.53 & 2.39 & -2.16 \\
\hline WB 1960-69 & -2.51 & 10.68 & 1.45 & 1.64 & -4.79 \\
\hline WB 1970-78 & 4.15 & 7.29 & -0.32 & -2.88 & 3.09 \\
\hline WB 1984-90 & 7.59 & 5.12 & 0.01 & -1.74 & 7.07 \\
\hline WB 1991-97 & -0.02 & 4.76 & -1.50 & 2.67 & -0.47 \\
\hline
\end{tabular}

Note: a: In line with Auffret (2003) I assume that $\rho=4$, which is consistent with empirical evidence. Source: Author's Computation based on data from NSS. 
Table 1 provides interesting information abut the distribution of the growth of real per capita consumption in these states. In Andhra Pradesh real per capita consumption growth was high and rising over the period but so was the standard deviation of consumption growth so that certainty equivalent consumption growth during 1991-97 was virtually the same as that between 1970-78. Except for 1984-90 Assam had low consumption growth. The standard deviation of consumption was such that except for 1984-90 certainty equivalent consumption growth was negative. Bihar, too, had low consumption growth with high standard deviations - particularly during 1960-69 and 1984-90. Certainty equivalent consumption growth was positive (but small in magnitude) only for 1970-78 and 1984-90. The growth of real per capita consumption in Gujarat was low during 1960-69 but picked up in the latter two periods, dropping off again in 1991-97. Standard deviations was moderately high but not rising with the result that except for 1960-69 certainty equivalent consumption growth has been positive. Karanataka's growth rates have fluctuated considerably. They were negative during 1960-69 and 1984-90 but strongly positive in the other two time periods. The standard deviation fell and then rose. Certainty equivalent consumption growth was positive in 1970-78 and 1991-97. Kerala had low growth rates in the first and last periods. However, the standard deviation in the last period was low so that certainty equivalent consumption growth was negative only during 1960-69. MP recorded buoyant growth with low standard deviation during 1984-90. Its consumption growth rate was negative during 1960-69 and 1991-97 and marginally positive during 1970-78. Certainty equivalent consumption growth was negative during 1960-69 and 1991-97. Consumption growth was high in Maharashtra only during 1970-78, although it was positive for all four periods. 1970-78 was the only period for which certainty equivalent consumption growth was positive. 
Consumption grew rapidly in Orissa during 1984-90 and less rapidly during 1970-78.

In the other two periods both actual consumption growth and certainty equivalent consumption growth were negative. Punjab also appears to have been subject to considerable consumption shocks. Both actual and certainty equivalent consumption growth were negative during 1960-69. Consumption growth was quite rapid during 1970-78 and 1984-90 during the heyday of the Green Revolution in that state but slackened off during 1991-97. Certainty equivalent consumption growth was positive during 1970-78, 1984-90 and 1991-97. Rajasthan had negative certainly equivalent consumption growth in all four periods despite the fact that actual consumption grew rapidly during 1970-78. Tamilnadu's growth rate rose steadily from 1960-69 before dropping off again during 1991-97. Except for 1960-69 certainty equivalent consumption growth has been positive. Except for 1984-90 UP has had low consumption growth. Except for 1984-90 certainty equivalent consumption growth has been negative. West Bengal enjoyed high consumption growth during 1970-78 and 1984-90. In the other two periods both actual consumption growth and certainty equivalent consumption growth were negative. Some of the observed patterns of actual and certainty equivalent consumption growth could be the result of the way the periods are constructed or because data from some of the NSS rounds $\left(26^{\text {th }}, 29^{\text {th }}, 30^{\text {th }}\right.$, $31^{\text {st }}, 33^{\text {rd }}, 34^{\text {th }}, 35^{\text {th }}, 36^{\text {th }}, 37^{\text {th }}, 39^{\text {th }}, 40^{\text {th }}, 41^{\text {st }}, 44^{\text {th }}, 47^{\text {th }}$ and $\left.49^{\text {th }}\right)$ have not been used. However, the basic point that in view of fluctuations in consumption growth certainty equivalent consumption growth has been lower than observed consumption growth in rural India has been made.

The pattern of consumption growth has shown hints of convergence. A regression of the average growth in actual consumption growth over the period 19581997 against the logs of real consumption per capita in these states has a strong 
negative coefficient, thus indicating that states that had relatively high per capita real consumption in 1958 grew less rapidly than states with low per capita real consumption. When this regression was run with average certainty equivalent growth rates and logs of real per capita consumption in 1958 the coefficient was again strongly negative. Hence, in both cases, there appears to be some convergence. However, in view of the volatility of the consumption growth figures, this result could change if a different base year was chosen.

\section{Conclusions}

Whereas much has been written about the evolution of real state gross domestic products of Indian states, relatively little has been said about the behaviour of consumption. In fact, consumption has, more often than not, been analysed only in the aggregate in macroeconomic analysis. What is undeniable, however, is that average consumption, under relatively small changes in distribution, is linked to living standards and is, therefore, a welfare measure of critical importance. This paper has emphasised the implications of one aspect of consumption - its variability - in India's rural sectors. It has argued that the high variability of consumption in the rural sector has led to certainty equivalent consumption growth being substantially lower than actual growth in many cases. Thus, welfare in India's rural sector has been rising more slowly than would be indicated by the movement in actual consumption growth or state GDP per capita growth. Such variability and the inability of rural consumers to smoothen consumption over time, partly due to poor or non-existent insurance facilities, have led to a situation where certainty equivalent consumption growth has been sluggish. This should be a matter of immense policy significance. 
Indeed it can be argued that the analysis in this paper is only suggestive, since the estimation has been done at the relatively aggregative level of individual states and data for recent time periods are not used. It would be useful to assess fluctuations in the average rates of growth at more disaggregated levels - say agro-climatic zones or even at the district or block level. This would blunt genuine concern that analysing consumption data at the level of states obfuscates distributional issues. Furthermore, the disaggregated analysis could be conducted using data collected involving consistent methodology post 1999-2000.

This analysis also has implications for the analysis of poverty. A statistical measure of poverty based on consumption or income at different points of time ignores the fact that variability of its consumption has an impact on the utility of the household. If a utility interpretation were given to the standard measures of poverty it would have to be that such standard measures of poverty implicitly assume that the consumption stream is certain. It could be that a household that is regarded as having risen from below the poverty line to above it during any time period may actually have experienced considerable variations in consumption during this period, so that in terms of certainly equivalent consumption the household may still be below the poverty line. Assessing vulnerability is, therefore, fundamental to any assessment of human welfare and an approach that focuses only on observed consumption at a point in time without reference to the history of such consumption, is subject to the risk of misrepresenting vulnerability. 


\section{References}

Auffret, P. (2003) 'High Consumption Volatility: The Impact of Natural Disasters?', Policy Research Working Paper 2962, The World Bank.

Auffret, P. (2002) 'The Importance of Financial and Insurance Market Integration in the Context of High Consumption Volatility in CGCED Countries', Washington, D.C.: The World Bank.

Chaudhuri, S., Jalan, J. and A. Suryahadi (2002) 'Assessing Household Vulnerability to Poverty from Cross Sectional Data: A Methodology and Estimates from Indonesia', Discussion Paper, Columbia University.

Datt, G. and M. Ravallion (1997) 'Macroeconomic Crisis and Poverty Monitoring,' Review of Development Economics, 1(2); 135-52.

Datt, G. and M. Ravallion (2002) 'Is India's Economic Growth Leaving the Poor Behind?', Journal of Economic Perspectives, 16(1): 89-108.

Gaiha, R. and K. Imai (2006) 'Vulnerability and Poverty in Rural India - Estimates for Rural South India', mimeo, IFAD, Rome.

Gaiha, R. and K. Imai (2004) 'Vulnerability, Persistence of Poverty and Shocks Estimates for Semi-Arid Rural India', Oxford Development Studies, 32(2): 261-81.

Hoddinott, J. and A. Quisumbing (2003a) 'Data Sources for Microeconometric Risk and Vulnerability Assessments', Social Protection Discussion Paper Series No. 0323, The World Bank.

Hoddinott, J. and A. Quisumbing (2003b) 'Methods for Microeconometric Risk and Vulnerability Assessments', Social Protection Discussion Paper Series No. 0324, The World Bank.

Jha, R. (2004) 'Reducing Poverty and Inequality in India: Has Liberalization Helped?', in G.A. Cornia (ed.) Inequality, Growth and Poverty in an Era of Liberalization and Globalization, New York: Oxford University Press, pp. 297-326.

Ligon, E. and L. Schechter (2003) 'Measuring Vulnerability', Economic Journal, 113(1): 95-102. 